\title{
Lymphocytic gastritis and associated small bowel disease: a diffuse lymphocytic gastroenteropathy?
}

\author{
D A F Lynch, G M Sobala, M F Dixon, A Gledhill, P Jackson, J E Crabtree, \\ A T R Axon
}

\begin{abstract}
Aim - To investigate the natural history of lymphocytic gastritis (LG) and its relation to Helicobacter pylori infection and to coeliac disease using serology, duodenal biopsy and a small intestinal permeability test.

Method - Twenty two patients diagnosed as having LG between 1984 and 1994 were investigated by upper gastrointestinal endoscopy at which gastric and duodenal biopsy specimens were taken for histological assessment and immunohistology. Serum was collected for measurement of anti-H pylori, anti-gliadin and anti-endomysial antibodies. A lactulose/mannitol absorption test was performed within one week of endoscopy. Control groups were studied by histology, serology and permeability tests.
\end{abstract}

Results - Three patients had been recently diagnosed as having LG while 15 still had the condition after a mean of 13.9 (range two to 38) months. LG involved the antrum alone in three patients, antrum and body in seven, body alone in six, and gastric remnant in two. Gastroduodenal intraepithelial lymphocytes (IELs) were $T$ cells and predominantly of $T$ suppressor (CD8) type. Duodenal IELs were increased compared to age/sex matched controls with chronic gastritis. Four patients had duodenal villous atrophy. Four patients no longer had LG after a mean of $29 \cdot 3$ (10-70) months but had increased gastroduodenal IELs. $H$ pylori was present in four (22\%) of 18 patients with LG but $H$ pylori serology was positive in $11(61 \%)$ of 18 . There was no difference in seropositivity when compared with age/sex matched controls with dyspepsia. Eleven of 20 patients with LG tested had abnormal lactulose/mannitol absorption ( $v$ none of 22 controls with chronic gastritis). Four patients with LG, all with villous atrophy, were seropositive for IgA endomysial antibody.

Conclusions - The persistence of LG with time, the association with increased duodenal IELs and abnormal small intestinal permeability suggests LG may be a manifestation of a diffuse lymphocytic gastroenteropathy related to sensitivity to gluten or some other agent.

(f Clin Pathol 1995;48:939-945)

Keywords: Lymphocytic gastritis, intraepithelial lymphocytes, small intestinal permeability, coeliac disease, Helicobacter pylori.
Lymphocytic gastritis is the histological counterpart of the macroscopic entity, varioliform gastritis. ${ }^{12}$ It is found in approximately $1 \%$ of gastric biopsy specimens from dyspeptic patients $^{23}$ and is characterised by an accumulation of lymphocytes in the surface and foveolar epithelium (fig 1). ${ }^{12}$ The normal stomach is devoid of intraepithelial lymphocytes (IELs) while in Helicobacter pylori associated chronic gastritis between four and seven lymphocytes per 100 epithelial cells are found. ${ }^{12}$ The diagnostic threshold for lymphocytic gastritis is usually taken as greater than 25 IELs per 100 cells. ${ }^{124}$ Endoscopically, there are enlarged rugal folds bearing nodular erosions principally involving the body of the stomach though in some cases of histological lymphocystic gastritis the endoscopic appearances may be normal. ${ }^{124}$

Little is known of the aetiology or natural history of lymphocytic gastritis. It has been attributed to an atypical response to $H$ pylori infection. ${ }^{2}$ However, while many patients are seropositive to the micro-organism, its presence is not usually confirmed histologically. ${ }^{2}$ It has also been suggested that lymphocytic gastritis may be a manifestation of coeliac disease. In one study of 22 patients with coeliac disease half had lymphocytic gastritis. The IELs in the stomach and small bowel were positive for MT-1, indicative of T cell infiltration. ${ }^{6}$ Two studies have reported that lymphocytic gastritis resolves after about two years, suggesting that the condition is transient. ${ }^{47} \mathrm{We}$ have investigated the natural history of lymphocytic gastritis and explored further the relation with $H$ pylori infection and small intestinal disease.

\section{Methods}

Thirty six patients with a histological diagnosis of lymphocytic gastritis made between 1984 and 1994 were approached for investigation. Three were recently diagnosed cases; 19 other patients agreed to undergo repeat endoscopy and biopsy. Prior to endoscopy, a full history was taken and clinical examination performed. Venous blood was taken for $H$ pylori serology and endomysial and gliadin antibody studies. Serum samples were stored at $-20^{\circ} \mathrm{C}$ until assayed. A lactulose/mannitol absorption test for the assessment of small intestinal permeability was performed within one week of the endoscopy. The study was approved by the local research ethics committee. 


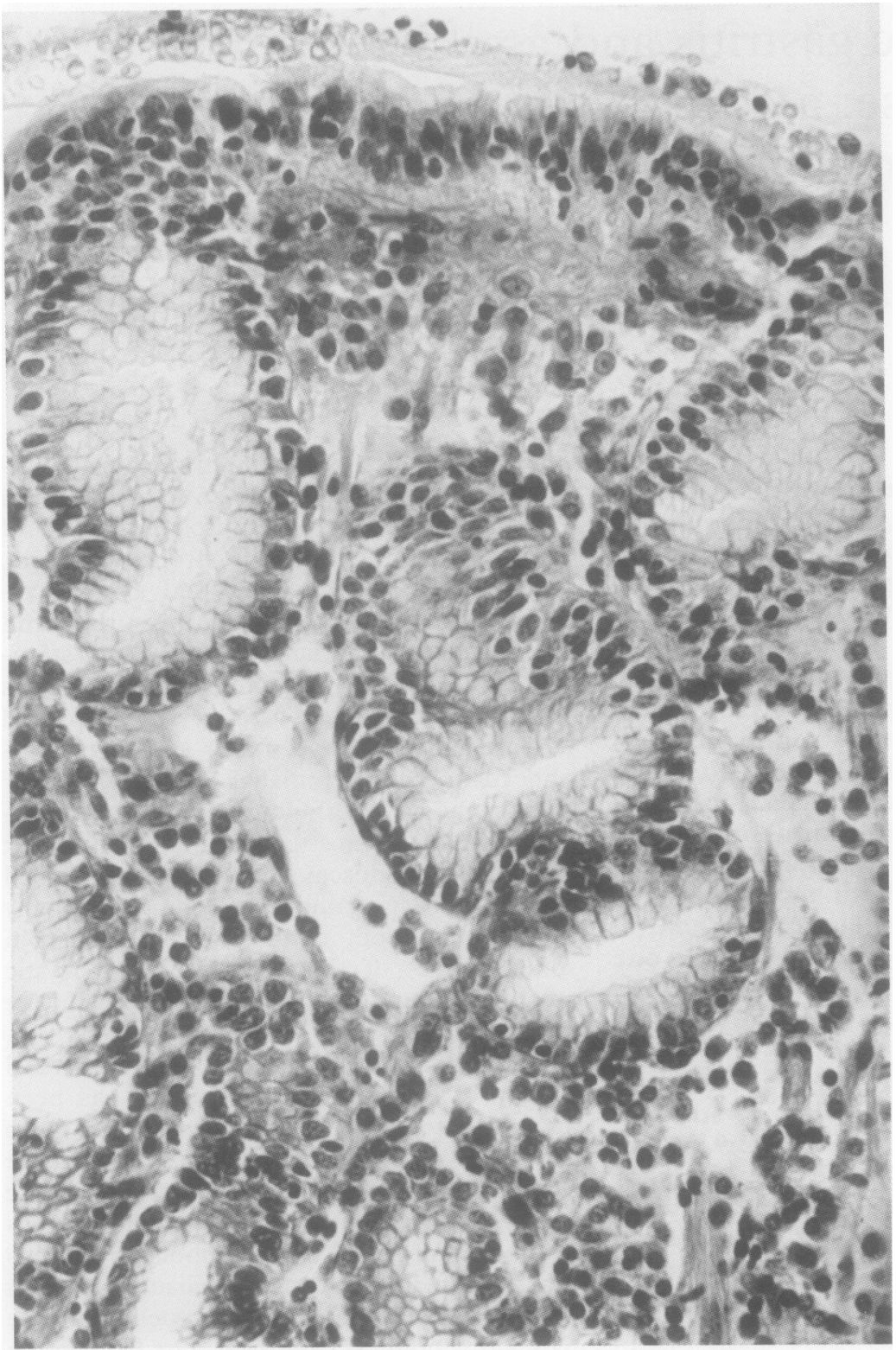

Figure 1 Microscopically, lymphocytic gastritis is characterised by increased numbers (greater than 25\%) of IELs in the surface and foveolar epithelium of the gastric mucosa. with lymphocytic gastritis, snap frozen in liquid nitrogen at $-80^{\circ} \mathrm{C}$ and sectioned. Immunostaining was performed using a three step immunoperoxidase technique. The following monoclonal antibodies (all from Dako, High Wycombe, UK) were used: anti-CD3 (pan T cell marker) at a 1 in 50 dilution; anti-CD22 (pan $\mathrm{B}$ cell) at a 1 in 100 dilution; anti-CD4 ( $\mathrm{T}$ helper (CD4) cell) at a 1 in 8 dilution; and anti-CD8 ( $\mathrm{T}$ cytotoxic-suppressor (CD8) cell) at a 1 in 25 dilution. Frozen tissue from four dyspeptic patients with normal gastric and duodenal mucosa on routine histology were used as controls.

\section{H PYLORI SEROLOGY}

Serum samples from all 22 test subjects were assayed for $H$ pylori IgG antibodies by an in house enzyme linked immunosorbent assay. ${ }^{8} \mathrm{~A}$ control group for the prevalence of positive $H$ pylori serology comprised 22 age/sex matched subjects who presented consecutively to our open access endoscopy clinic with a history of dyspepsia.

\section{GLIADIN AND ENDOMYSIAL ANTIBODIES}

Serum IgA, IgG and IgM anti-gliadin antibodies (AGA) were measured in all 22 test subjects using a previously described method. ${ }^{9}$ The control group comprised 22 healthy subjects used by Mwantembe and Ferguson (unpublished data). Serum samples were also assayed for IgA endomysial antibodies (EMA) using a method described previously. ${ }^{10}$

\section{LACTULOSE/MANNITOL ABSORPTION}

Small intestinal permeability was determined using this standard non-invasive technique in 20 subjects. ${ }^{11}$ The normal urinary lactulose/ mannitol ratio is 0.07 or lower. A group of 22 patients with a similar age/sex distribution

Table 1 Clinical details of patients with current and

HISTOLOGY

At endoscopy, a single biopsy specimen was taken from the second part of the duodenum, gastric antrum and body using standard biopsy forceps. Specimens were fixed in $10 \%$ buffered formalin, embedded in paraffin wax, and stained with haematoxylin and eosin. A modified Giemsa stain was used to detect $H$ pylori. The haematoxylin and eosin stained sections were examined at $\times 400$ magnification and the number of IELs and epithelial cell nuclei in an uninterrupted length of surface and foveolar epithelium were counted. At least 500 epithelial cells were counted and the results expressed as lymphocytes per 100 epithelial cells. For the purpose of comparison we took biopsy specimens of the same sites from age/sex matched patients undergoing endoscopy for dyspeptic symptoms, and found to have $H$ pylori associated gastritis.

\section{IMMUNOHISTOLOGY}

Additional duodenal and gastric biopsy specimens were taken as above from seven patients

\begin{tabular}{|c|c|c|c|c|}
\hline $\begin{array}{l}\text { Patient } \\
\text { no. }\end{array}$ & $\begin{array}{l}\text { Age } \\
\text { (years) }\end{array}$ & Sex & $\begin{array}{l}\text { Interval } \\
\text { (months)* }\end{array}$ & $O G D$ \\
\hline \multicolumn{5}{|c|}{ Current lymphocytic gastritis } \\
\hline 1 & 40 & $\mathrm{~F}$ & 30 & VG \\
\hline 2 & 68 & $\mathbf{M}$ & 15 & $\mathrm{AE}$ \\
\hline$\overline{3}$ & 59 & $\mathbf{M}$ & 15 & PG \\
\hline 4 & 61 & $\mathrm{~F}$ & 38 & $\mathbf{N}$ \\
\hline 5 & 44 & $\mathbf{M}$ & 2 & $\mathbf{N}$ \\
\hline 6 & 24 & $\mathbf{M}$ & 22 & $\mathrm{~N}$ \\
\hline 7 & 88 & $\mathrm{~F}$ & 2 & $\mathbf{N}$ \\
\hline 8 & 26 & $\mathrm{~F}$ & 2 & VG \\
\hline 9 & 78 & $\mathrm{~F}$ & 2 & $\mathrm{~N}$ \\
\hline 10 & 70 & $\mathbf{M}$ & 2 & HDU \\
\hline 11 & 47 & $\mathrm{~F}$ & 2 & VG \\
\hline 12 & 55 & $\mathbf{M}$ & 21 & $\mathbf{N}$ \\
\hline 13 & 39 & $\mathbf{M}$ & 9 & $\mathbf{N}$ \\
\hline 14 & 45 & $\mathbf{M}$ & 15 & VG \\
\hline 15 & 60 & $\mathbf{F}$ & 31 & GE \\
\hline 16 & 55 & $\mathbf{M}$ & - & VG \\
\hline 17 & 69 & $\mathrm{~F}$ & - & $\mathbf{N}$ \\
\hline 18 & 59 & F & - & $\mathbf{N}$ \\
\hline \multicolumn{5}{|c|}{ Previous lymphocytic gastritis } \\
\hline 19 & 69 & M & 13 & $\mathrm{~N}$ \\
\hline 20 & 23 & $\mathrm{M}$ & 70 & $\mathbf{N}$ \\
\hline 21 & 39 & $\mathrm{~F}$ & 24 & $\mathbf{N}$ \\
\hline 22 & 66 & $M$ & 10 & VG \\
\hline
\end{tabular}
* Time interval from original diagnosis of lymphocytic gastritis.
OGD=oesophagogastroduodenoscopy; $\mathrm{N}=$ normal; $\mathrm{VG}=\mathrm{va}-$ OGD = oesophagogastroduodenoscopy; $\mathrm{N}=$ normal; $\mathrm{VG}=\mathrm{va}-$ rioliform gastritis; $\mathrm{HDU}=$ healed duodenal ulcer; $\mathrm{AE}=$ antra
erythema; $\mathrm{PG}=$ partial gastrectomy; $\mathrm{GE}=$ gastroenterostomy. 


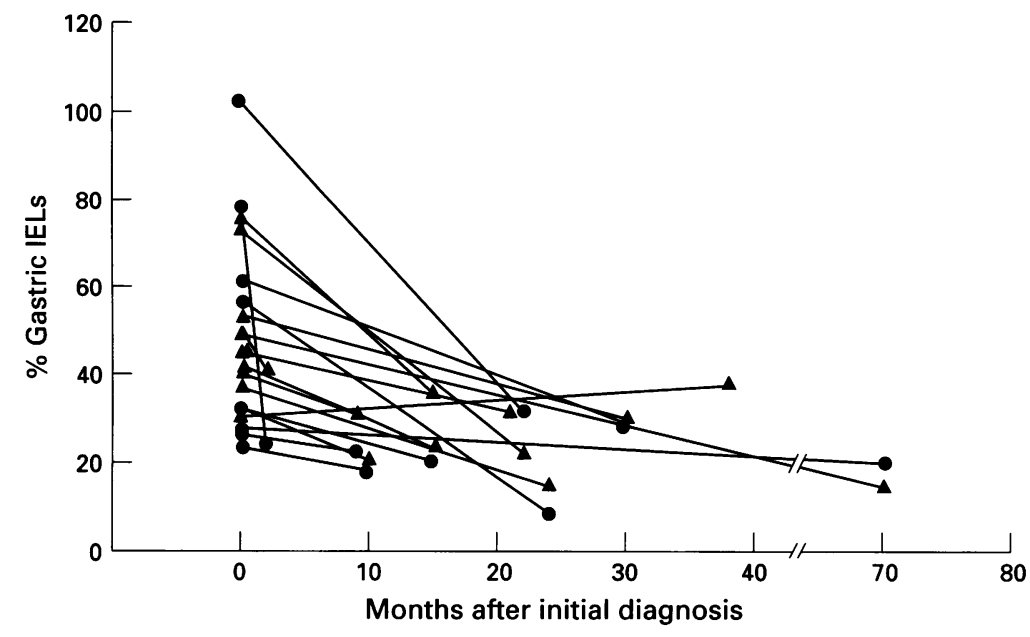

Figure 2 Demonstrates the change in gastric IEL numbers in patients with lymphocytic gastritis over time (paired biopsy specimens from 11 patients; antrum = 8, body=11).

There is a significant reduction in gastric IEL numbers over time $(p=0.0005$; Wilcoxon signed rank test). However, the number of gastric IELs is still greater than that present in control subjects with $\mathrm{H}$ pylori gastritis. O, Antrum; $\mathbf{\Delta}$, body mucosa.

undergoing routine diagnostic endoscopy, and found to have chronic gastritis (with or without $H$ pylori infection), were used as controls.

\section{STATISTICAL ANALYSIS}

For comparison of unpaired non-parametric data the Mann-Whitney U test was used. A p value less than 0.05 was regarded as significant.

\section{Results}

ENDOSCOPY

Of those patients with current lymphocytic gastritis, endoscopy was normal in nine. One showed erythema with thickening of the antral mucosal folds, while five had multiple small elevated plaques with superficial ulceration in the body and antrum. One of these had a healing ulcer in the duodenal cap. One patient had a partial gastrectomy and another had a gastroenterostomy for peptic ulcer disease, while another had a healed duodenal ulcer. Of the four patients who no longer had lymphocytic gastritis, three were normal and one still had the typical varioliform appearance (table 1).

\section{HISTOLOGY}

Three patients had recently been diagnosed as having lymphocytic gastritis. Fifteen of the remaining 19 patients had persisting lymphocytic gastritis a mean of 13.9 months (range two to 38) after the original diagnosis. This group of 18 patients will be referred to as patients with current lymphocytic gastritis (table 1). The gastric antrum and body were involved in seven patients, antrum alone in three, body alone in six, and gastric remnant in two. In patients with current lymphocytic gastritis the median IEL count in the antrum was $27 \cdot 5 \%$ (interquartile range $23-31$ ) and was $32.5 \%(28-38.5)$ in the body. There was no significant difference between the antral and body IEL counts. Duodenal (second part) his- tology was normal in 14 patients. Three patients had severe villous atrophy of the duodenum and one patient had marked villous atrophy in a jejunal biopsy. The median duodenal IEL count in the patients with current lymphocytic gastritis was $19 \%(14 \cdot 6-22 \cdot 8)$.

Four patients no longer had lymphocytic gastritis after a mean of $29 \cdot 3$ months (range 10-70) and will be referred to as patients with previous lymphocytic gastritis. In patients with previous lymphocytic gastritis the gastric and duodenal mucosal sections were described as histologically normal. However, antral and body IEL counts were $17 \%(8-19)$ and $14 \%$ (14-20), respectively. The median duodenal IEL count in patients with previous lymphocytic gastritis was $17 \%(14-20)$. The antral, body and duodenal IEL counts in all patients with lymphocytic gastritis (current and previous) were significantly higher than in the controls (control values: duodenum, 9.5\% (711) ( $<<0.001)$; antrum, $7 \%(5.3-8)(\mathrm{p}<0.001)$; body, $6 \%(3.3-8)(p<0.001))$.

Adequate biopsy specimens from both antrum and corpus were available from the initial diagnostic endoscopy in only 11 patients for comparison with the follow up biopsy specimens. Gastric IELs were counted in these paired biopsy specimens (seven with current lymphocytic gastritis and four with previous lymphocytic gastritis). The initial and follow up counts are shown in fig 2 . There was a significant $(p=0.0005)$ fall in IEL counts with time.

\section{H PYLORI HISTOLOGY AND SEROLOGY}

$H$ pylori was found on histology in four of 18 patients with current lymphocytic gastritis. One patient found to have duodenal villous atrophy had been $H$ pylori positive in the past and had been treated, six months previously, with a two week course of anti-helicobacter triple therapy comprising tetracycline, bismuth complex and metronidazole. He is currently negative for $H$ pylori histologically. Furthermore, $H$ pylori serology was also negative. None of the four patients with previous gastritis were $H$ pylori positive. Eleven of the 18 patients with current lymphocytic gastritis were seropositive, six were seronegative, and one was borderline. Three of four patients with previous lymphocytic gastritis tested were seronegative (table 2). Seventeen of 22 random dyspeptic control subjects were seropositive, one was borderline and four were seronegative for $H$ pylori. The difference in seropositivity between patients with lymphocytic gastritis and the control group was not statistically significant.

\section{IMMUNOHISTOLOGY}

Seven patients with current lymphocytic gastritis were studied. The duodenal and gastric IELs were virtually all positive for CD3. There was no positive staining of IELs for CD22. The IELs were predominantly of CD8 $+\mathrm{T}$ cytotoxic suppressor type, the remainder being $\mathrm{CD} 4+\mathrm{T}$ cells. In order to determine whether there was a shift in the proportion of CD8 IELs 
Table 2 Laboratory findings

\begin{tabular}{|c|c|c|c|c|c|c|c|}
\hline \multirow{2}{*}{$\begin{array}{l}\text { Patient } \\
\text { no. }\end{array}$} & \multicolumn{2}{|l|}{ H pylori } & \multicolumn{3}{|c|}{$\%$ IELs (haematoxylin and eosin) } & \multirow{2}{*}{$\begin{array}{l}\text { Lactulose/mannitol } \\
\text { (normal range } 0-0.07 \text { ) }\end{array}$} & \multirow{2}{*}{$\begin{array}{l}\text { Duodenal } \\
\text { histology }\end{array}$} \\
\hline & Histology & Serology & D2 & $A$ & $B$ & & \\
\hline \multicolumn{8}{|c|}{ Current lymphocytic gastritis } \\
\hline 1 & - & + & 24 & 28 & 29 & 0.05 & Normal \\
\hline 2 & - & + & 19 & 20 & 35 & 0.22 & Normal \\
\hline 3 & - & + & 22 & - & 28 & 0.04 & Normal \\
\hline 4 & - & + & 17 & 27 & 37 & $0 \cdot 20$ & Normal \\
\hline 5 & + & - & 21 & 24 & 39 & $0 \cdot 15$ & Normal \\
\hline 6 & - & - & 17 & 31 & 21 & 0.03 & Normal \\
\hline 7 & - & + & 12 & 23 & 31 & 0.02 & Normal \\
\hline 8 & - & $-1+$ & 23 & 28 & 16 & $0 \cdot 18$ & Normal \\
\hline 9 & - & + & 19 & 28 & 45 & 0.08 & Normal \\
\hline 10 & + & + & 11 & 34 & 24 & $0 \cdot 08$ & Normal \\
\hline 11 & - & - & 17 & 18 & 34 & 0.04 & Normal \\
\hline 12 & + & + & 18 & 26 & 31 & 0.03 & Normal \\
\hline 13 & + & + & 14 & 22 & 31 & $0 \cdot 08$ & Normal \\
\hline 14 & - & - & 26 & 39 & 46 & 0.26 & VA \\
\hline 15 & - & + & VA & - & 42 & NA & VA \\
\hline 16 & - & - & 12 & 23 & 48 & 0.03 & Normal \\
\hline 17 & - & + & 41 & 43 & 38 & $0 \cdot 15$ & VA \\
\hline 18 & - & - & 40 & 34 & 28 & 0.01 & VA \\
\hline \multicolumn{8}{|c|}{ Previous lymphocytic gastritis } \\
\hline 19 & - & - & 16 & 8 & 14 & NA & Normal \\
\hline 20 & - & - & 20 & 19 & 14 & 0.06 & Normal \\
\hline 21 & - & - & 17 & 15 & NA & 0.08 & Normal \\
\hline 22 & - & NA & 14 & 18 & 20 & $0 \cdot 11$ & Normal \\
\hline
\end{tabular}

$\mathrm{D} 2=$ second part of the duodenum; $\mathrm{A}=$ antrum; $\mathrm{B}=$ body; $\mathrm{VA}=$ villous atrophy; $\mathrm{NA}=$ not available. Abnormal values appear in bold.

Table 3 Median ratios and ranges of $C D 8+T$ cells to total IEL numbers (CD8 + and CD4 + cells) in duodenal, antral and body mucosa in seven patients with lymphocytic gastritis and in sex/age matched controls

\begin{tabular}{llr}
\hline Anatomical site & Current lymphocytic gastritis & Controls \\
\hline Duodenum & $89 \%(65-100)$ & $100 \%(75-100)$ \\
Antrum & $91 \%(67-100)$ & $89 \%(80-100)$ \\
Body & $84 \%(68-100)$ & $97 \%(61-100)$ \\
\hline
\end{tabular}

the $\mathrm{CD} 8 / \mathrm{CD} 8+\mathrm{CD} 4$ ratios were calculated (table 3 ). There was no significant difference in gastroduodenal CD8/CD4 ratios between patients with lymphocytic gastritis and control subjects.

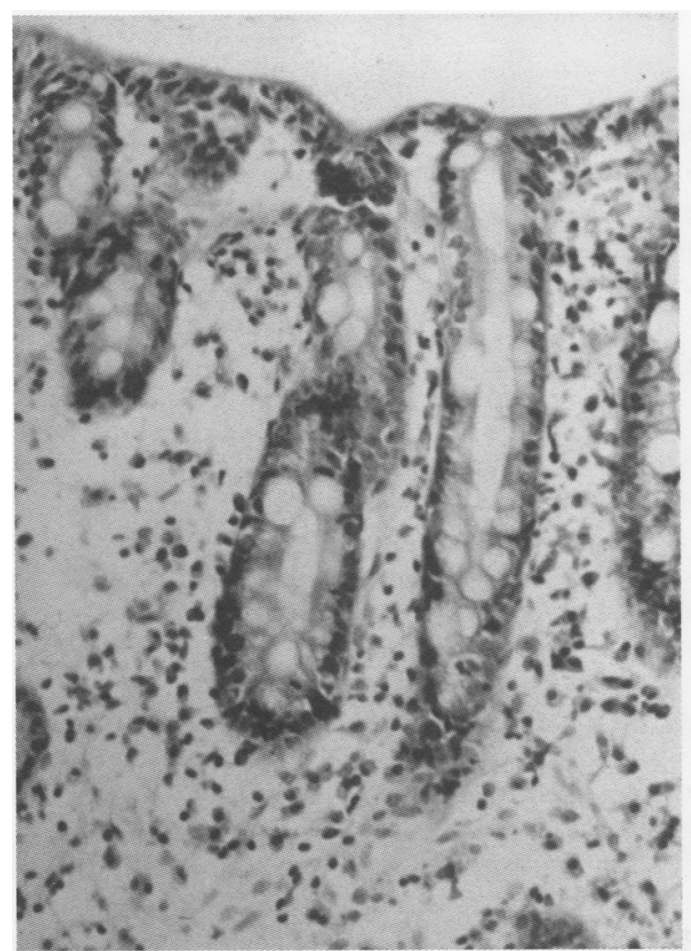

LACTULOSE/MANNITOL ABSORPTION

Nine of 17 patients with current lymphocytic gastritis, including three patients with villous atrophy, had abnormal small intestinal permeability. Two out of three patients with previous lymphocytic gastritis tested had abnormal lactulose/mannitol absorption (table 2). None of the 22 control subjects (median age 53 (range 21-73) years; 13 females) had abnormal small intestinal permeability (mean (SD), 0.327 $(0.021)$, range $0 \cdot 01-0 \cdot 07)$.

RESPONSE TO GLUTEN WITHDRAWAL

Two of the four patients with lymphocytic gastritis and villous atrophy were placed on a gluten

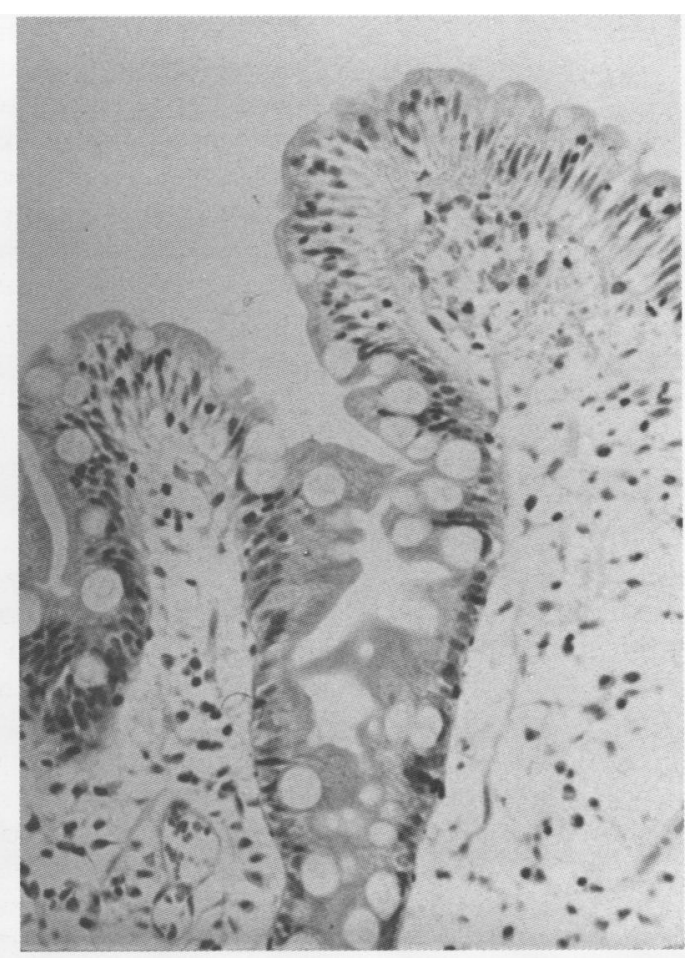

Figure 3 Duodenal (second part) biopsy specimens from a patient with lymphocytic gastritis and villous atrophy before (left) and after (right) three months of treatment with a gluten free diet. 
Table 4 Serum levels of anti-gliadin antibodies in patients with lymphocytic gastritis and age/sex matched controls

\begin{tabular}{llll}
\hline Group & $\begin{array}{l}I g A \\
(\mathrm{mg} / \mathrm{ml})\end{array}$ & $\begin{array}{l}I g G \\
(\mathrm{mg} / \mathrm{ml})\end{array}$ & $\begin{array}{l}I g M \\
(\mathrm{mg} / \mathrm{ml})\end{array}$ \\
\hline Controls $(\mathrm{n}=23)$ & $7(2-35)$ & $27(4-60)$ & $37(15-86)$ \\
Lymphocytic gastritis $(\mathrm{n}=22)$ & $8(3-49)$ & $32(9-85)$ & $46(9-131)$ \\
& $\mathrm{p}=0 \cdot 15$ & $\mathrm{p}=0.042$ & $\mathrm{p}=0.33$ \\
\hline
\end{tabular}

There was no difference between the two groups when assayed for serum IgA and IgM. However, serum IgG AGA is increased in lymphocytic gastritis.

free diet. Both patients showed evidence of clinical and biochemical improvement. One patient who had varioliform gastritis at presentation, underwent a repeat endoscopy three months after gluten withdrawal. The endoscopic appearances were improved; there were no superficial erosions but the gastric mucosal folds remained slightly thickened. There was also a marked improvement in villous morphology in the duodenum (fig 3) but no change in the IEL counts (26-29\%). However, there was a non-significant reduction in the antral and body mucosa IEL counts from 39 to $32 \%$ and from 46 to $32 \%$, respectively.

\section{GLIADIN AND ENDOMYSIAL ANTIBODIES}

Fourteen of 18 patients with current lymphocytic gastritis were seronegative for IgA EMA. The four patients with duodenal or jejunal villous atrophy were seropositive. There was no significant difference between patients with current or previous lymphocytic gastritis compared with the control group when assayed for IgA and IgM AGA. Subjects with lymphocytic gastritis had increased serum IgG AGA (table 4). However, if patients with villous atrophy were excluded from analysis no difference was observed.

\section{Discussion}

Previous studies have suggested that lymphocytic gastritis resolves after about two years. ${ }^{47}$ While our results show that there is a reduction in gastric IEL counts over time (fig 2), three patients had the condition up to three years after the original diagnosis. Furthermore, patients with "resolved" or previous lymphocytic gastritis, which appears normal on routine histological examination, have significantly higher gastric mucosal IEL counts than controls. Thus, the resolution is a lowering of the number of IELs below the diagnostic cut off level of $25 \%$ and not a return to normal. This suggests that the increased IEL infiltrate, albeit in some cases at a lower level than that required for a diagnosis of lymphocytic gastritis, is a persistent phenomenon. We confirm that the IELs are $T$ cells and that the majority are of $T$ suppressor type (CD8). As in previous studies ${ }^{12}$ we have found that the histological distribution of lymphocytic gastritis varies throughout the stomach. The antrum and body can be involved independently or together. However, the entire gastric mucosa in patients with lymphocytic gastritis is histologically abnormal. While the IELs are not present in some areas in sufficient numbers for a diagnosis of lymphocytic gastritis, they are higher than in controls. We also confirm that lymphocytic gastritis varies in its endoscopic appearance. ${ }^{124}$ It can take on the classic diffuse varioliform gastritis picture or the antral folds alone may appear red and thickened. In a minority of patients the endoscopic appearances may be normal.

In this study four patients with lymphocytic gastritis had severe villous atrophy consistent with coeliac disease. We have also found that patients with lymphocytic gastritis and normal villous architecture have increased IEL numbers in their duodenal mucosa. While an increased prevalence of lymphocytic gastritis has been reported in coeliac disease, ${ }^{6}$ a previous study of patients with lymphocytic gastritis did not detect any small bowel abnormality on standard histological examination. ${ }^{4}$ Increased small intestinal IEL counts are present in patients with treated coeliac disease following gluten challenge, ${ }^{12}$ dermatitis herpetiformis, ${ }^{13}$ first degree relatives of patients with coeliac disease, ${ }^{14}$ and those with low grade small intestinal enteropathy. ${ }^{15}$ The finding of increased IEL numbers in the duodenal mucosa and, in two cases, the beneficial effects of gluten withdrawal, lend some support to the hypothesis that lymphocytic gastritis is another manifestation of a gluten related enteropathy.

The finding of abnormal small intestinal permeability in patients with current and previous lymphocytic gastritis without histological evidence of villous atrophy is of iinterest. Only one patient (case 16) was taking non-steroidal antiinflammatory drugs and his permeability test was normal. Our results suggest that lymphocytic gastritis per se is associated with impaired small bowel function. This finding should prompt a re-appraisal of the reported link between lymphocytic gastritis and a protein losing gastropathy which was first recognised by Crampton et al. ${ }^{16}$ These authors described two patients in a protein losing state in whom there were thickened gastric folds with lymphocytic gastritis but no histological evidence of Menetrier's disease. Duodenal biopsy specimens showed a marked increase in IEL numbers. Further cases of lymphocytic gastritis associated with hypoproteinaemia have been described subsequently. ${ }^{1718}$ It is also noteworthy that one patient in a series with abnormal small intestinal absorption, who did not have histological evidence of coeliac disease using standard histological techniques, had multiple elevated gastric erosions at endoscopy. ${ }^{19}$

The anti-endomysial and anti-glidian results in our patients, apart from the positive EMA in the patients with villous atrophy, are not surprising. It is becoming evident that antibodies to gluten or its components are epiphenomena that reflect small bowel mucosal damage ${ }^{13}$ in response to gluten. Abnormal small intestinal permeability occurs in the presence of normal jejunal histology and morphology in dermatitis herpetiformis ${ }^{20}$ and in relatives of patients with coeliac disease. ${ }^{21}$ Furthermore, it has been demonstrated to precede the development of coeliac disease. ${ }^{22}$

Latent gluten sensitive enteropathy occurs 
in apparently healthy and first degree relatives of patients with coeliac disease. Differing degrees of sensitivity to gluten are believed to account for the geographical variation in the incidence of coeliac disease and the spectrum of histological changes from complete villous atrophy to normal jejunal mucosa..$^{923-27}$ Inappropriate immune reactions to gliadin occur in the mouth ${ }^{28}$ and the rectum ${ }^{29}$ and recently an association between lymphocytic colitis and coeliac disease has been described. ${ }^{30}$ Therefore gastric mucosal involvement is not unexpected. Coeliac disease is associated with an increased incidence of gastritis and abnormal gastric function which has previously been attributed to an autoimmune gastritis. ${ }^{31-33}$ However, the incidence of autoimmune gastritis has been found to be low in coeliac disease ${ }^{34}$ whereas gastric mucosal IEL numbers are increased. ${ }^{635}$ Co-existent lymphocytic gastritis may account, in part, for these abnormalities.

Using serology, we have found no difference in the prevalence of $H$ pylori antibodies in patients with lymphocytic gastritis compared with dyspeptic controls. The relatively low prevalence of the organism on histology ${ }^{4}$ when compared with the usual chronic (type B) gastritis, and the discrepancy between the histological and serological $H$ pylori status in patients with lymphocytic gastritis is consistent with a previous study. ${ }^{2}$ However, a negative histological result might not necessarily mean that infection is absent. False negative results could be explained by inadequacies in techniquethat is, the bacteria could be present in very small numbers and not recognised in the sections. Alternatively, they may have adopted the coccoid form in response to the hostile environment brought about by the mucosal inflammatory response. Sensitive methods of detection such as in situ hybridisation or a polymerase chain reaction technique would clarify this point. While it is possible that lymphocytic gastritis is a manifestation of an effective, but unusual, host immune response to $H$ pylori, it may be completely unrelated to infection. It is certainly apparent that in most cases the process persists in an active form in the absence of $H$ pylori infection. However, an alternative explanation is that $H$ pylori infection triggers an immunopathological process in the gastric mucosa of predisposed individuals, possibly by the enhanced expression of class II HLA, ${ }^{36}$ in much the same way as latent gluten enteropathy could be unmasked by intestinal infection and lead to its presentation as overt adult onset coeliac disease. ${ }^{27}$

In conclusion, we have found that gastric mucosal IELs remain persistently elevated in subjects with lymphocytic gastritis, refuting previous suggestions that the disease is transient. The finding of duodenal villous atrophy in four patients, and the presence of increased duodenal IEL numbers and abnormal small intestinal permeability in other patients, leads one to speculate that lymphocytic gastritis represents part of a diffuse lymphocytic gastroenteropathy which varies in its expression from site to site. Thus, coeliac disease represents a primary small intestinal disorder which is accompanied by intraepithelial lymphocytosis in the stomach, while lymphocytic gastritis is primarily a gastric disorder accompanied by intraepithelial lymphocytosis and functional disturbances in the small intestine. On rare occasions, coeliac disease and fully developed (varioliform) lymphyocytic gastritis co-exist. Whether these two conditions represent abnormal immune reactions to a common antigen related to gluten or to totally different antigens awaits further investigation. Likewise, the relation of lymphocytosis in the large intestine to coeliac disease and lymphocytic gastritis requires further study. It is possible that lymphocytic colitis is another manifestation of a mucosal immune response to luminal antigen, which in this instance is maximally expressed in the large intestine. A comparison of HLA status and the antigen responsiveness of gastrointestinal lymphocytes in patients with lymphocytic gastritis, lymphocytic colitis and coeliac disease would add greatly to our understanding of the inter-relations between these intriguing conditions.

We would like to thank Professor A Ferguson and $\mathrm{Mr} \mathrm{N}$ Anderson for performing the anti-gliadin assays.

1 Haot J, Hamichi L, Wallez L, Mainguet P. Lymphocytic gastritis: a newly described entity: a retrospective endoscopic and histological study. Gut 1988;29:1258-64.

2 Dixon MF, Wyatt J, Burke DA, Rathbone BJ. Lymphocytic gastritis: relationship to Campylobacter pylori infection. gastritis: relationship to Cam

3 Jaskiewicz K, Price SK, Zak J, Louwrens HD. Lymphocytic gastritis in nonulcer dyspepsia. Dig Dis Sci 1991;36:1079 83.

4 Jones EA, Flejou J-F, Potet F, Muzeau F, Molas G, Rotenburg A, et al. Lymphocytic gastritis: a clinicopathological study of 32 patients. Eur $\mathcal{F}$ Gastroenterol Hepatol 1990;2: 367-72.

5 Tsuneoka K, Takemoto I, Fukuchi S. In: Fiberoscopy of gastric diseases. Stuttgart: Fischer, 1973.

6 Wolber R, Owen D, del Buono L, Appelman H, Freeman H. Lymphocytic gastritis in patients with celiac sprue or sprue like intestinal disease. Gastroenterology 1990;98: 310-15.

7 Delos M, Mourin-Jouret A, Wallez L, Willette M, Mainguet $\mathrm{P}$, Haot J. Evolution histologique d'un série de gastrites caractérisées par une infiltration lymphocytaire intra-épicaractérisées par une infiltration lympho

8 Crabtree JE, Mahony MJ, Taylor JD, Heatley RV, Littlewood JM, Tompkins DS. Immune responses to Helicobacter pylori in children with recurrent abdominal pain. $\mathcal{F}$ Clin Pathol 1991;44:768-71.

9 Ferguson A, Blackwell JN, Barnetson RStC. Effects of additional dietary gluten on the small-intestinal mucosa of volunteers and of patients with dermatitis herpetiformis. Scand $\mathcal{F}$ Gastroenterol 1987;22:543-9.

10 Burgin-Wolff A, Gaze $H$, Hadziselimovic F, Huber $H$, Lentze MJ, Nussle $\mathrm{D}$, et al. Antigliadin and antiendomysium antibody determination for coeliac disease. Arch Dis Child 1991;66:941-7.

11 Menzies IS. Absorption of intact oligosaccharides in health and disease. Biochem Soc Trans 1974;2:1042-7.

12 Marsh MN. Studies of intestinal lymphoid tissue. XI - The immunopathology of cell-mediated reactions in gluten sensitivity and other enteropathies. Scanning Microsc 1988; 2:1663-84

13 Gawkrodger DJ, McDonald C, O'Mahony S, Ferguson A. Small intestinal function and dietary status in dermatitis herpetiformis. Gut 1991;32:377-82.

14 Marsh MN, Bjarnason I, Shaw J, Ellis A, Baker R, Peters TJ. Studies of intestinal lymphoid tissue XIV-HLA status, mucosal morphology, permeability and epithelial lymphocyte populations in first degree relatives of patients with coeliac disease. Gut 1990;31:32-6.

15 Marsh MN. Gluten, major histocompatibility complex, and the small intestine. A molecular and immunologic approach to the spectrum of gluten sensitivity ("celiac proach to the spectrum of gluten sensitivi

16 Crampton JR, Hunter JO, Neale G, Wight DGD. Chronic lymphocytic gastritis and protein losing enteropathy. Gut 1989;30(Festschrift):71-4.

17 Wolber RA, Owen DA, Anderson FH, Freeman HJ. Lymphocytic gastritis and giant gastric folds associated with gastrointestinal protein loss. Mod Pathol 1991;4:13-15.

18 Farahat $K$, Hainaut $P$, Jamar $F$, Haot J, Lambert $M$ Lymphocytic gastritis: an unusual cause of hypoproteinaemia. f Intern Med 1993;234:95-100. 
19 Juby LD, Rothwell J, Axon ATR. Cellobiose/mannitol sugar test-a sensitive tubeless test for coeliac disease: results
on 1010 unselected patients. Gut $1989 ; 30: 476-80$.

20 O'Mahony S, Vestey JP, Ferguson A. Similarities in humoral immunity in dermatitis herpetiformis without enteropathy and in coeliac disease. Lancet 1990;335:1487-90.

21 van Elburg RM, Uil J, Mulder CJ, Heymans HSA. Intestinal permeability in patients with coeliac disease and relatives of patients with coeliac disease. Gut 1993;34: 354-7.

22 Hall EJ, Batt RM. Abnormal permeability precedes the development of a gluten sensitive enteropathy in Irish setter dogs. Gut 1991;32:749-53.

23 Doherty M, Barry RE. Gluten-induced mucosal changes in subjects with overt small bowel disease. Lancet 1981; 517-20.

24 Logan RFA, Rifkind EA, Busuttil A, Gilmour HM, Ferguson A. Prevalence and "incidence" of coeliac disease in Edinburgh and the Lothian region of Scotland. Gastro enterology 1986;90:334-42.

25 Cooper BT, Holmes GKT, Ferguson R, Thompson RA, Allan RN, Cooke WT. Gluten-sensitive diarrhoea withou evidence of coeliac disease. Gastroenterology 1980;79:801-6.

26 Arnason JA, Gudjonsson H, Freysdottir J, Jonsdottir I, Valdimarsson $\mathrm{H}$. Do adults with high gliadin antibody concentrations have subclinical gluten intolerance? Gut 1992;33:194-7.

27 Ferguson A, Arranz E, O'Mahony S. Clinical and patho- logical spectrum of coeliac disease-active, silent, latent, potential. Gut 1993;34:150-1.

28 Wray D. Gluten-sensitive recurrent aphthous stomatitis. Dig Dis Sci 1981;26:737-40.

29 Cooke WT, Peeney ALP, Hawkins CF. Symptoms, sign and diagnostic features of idiopathic steatorrhoea. $Q \mathcal{F}$ Med 1953;22:59.

30 Armes J, Gee DC, MaCrae FA, Schroeder W, Bathal PS Collagenous colitis: Jejunal and colorectal pathology. $\mathcal{f}$ Clin Pathol 1992;45:784-7.

31 Hansky J, Shiner M. Gastric studies in idiopathic steatorrhoea. Gastroenterology 1963;45:49-56.

32 Gillberg R, Kastrup W, Mobacken H, Stockbrugger R Ahren C. Gastric morphology and function in dermatitis herpetiformis and in coeliac disease. Scand 7 Gastroenterol 1985;20:133-40.

33 O'Donoghue DP, Lancaster-Smith M, Johnson GD, Kumar PJ. Gastric lesion in dermatitis herpetiformis. Gut 1976; 17:185-8.

34 Crabtree JE, O'Mahony S, Wyatt JI, Heatley RV, Vestey JE Howdle $\mathrm{PD}$, et al. Helicobacter pylori serology in patients with coeliac disease and dermatitis herpetiformis. $\mathcal{F}$ Clin Pathol 1992;45:597-600.

35 Karttunen T, Niemela S. Lymphocytic gastritis and coeliac disease [letter]. 7 Clin Pathol 1990;43:436-7.

36 Wee A, Teh M, Kang JY Association of Helicobacter pylor with HIA-DR antigen expression in gastritis. 7 Clin Pathol 1992;45:30-3. 